\title{
Electrical Properties of Cadmium Substitution in Nickel Ferrites
}

\author{
Ande Ashok ${ }^{1}$, Thatikonda Somaiah ${ }^{2}$, Dachepalli Ravinder ${ }^{3}$, Chinnala Venkateshwarlu ${ }^{2}$, \\ Chandiri Sudhakar Reddy ${ }^{4}$, Kappera Nageshwar $\operatorname{Rao}^{4}$, Meesala Prasad ${ }^{1}$ \\ ${ }^{1}$ Department of Physics, Osmania University, Hyderabad, India; ${ }^{2}$ Department of Physics, University College of Science, Osmania \\ University, Hyderabad, India; ${ }^{3}$ Department of Physics, Nizam College, Basheerbagh Osmania University, Hyderabad, India; \\ ${ }^{4}$ Department of Chemistry, University College of Science, Osmania University, Hyderabad, India. \\ Email: ravindergupta28@rediffmail.com
}

Received March $2^{\text {nd }}, 2012$; revised April $7^{\text {th }}, 2012$; accepted April $18^{\text {th }}, 2012$

\begin{abstract}
Electrical transport properties such as conductivity $(\sigma)$ and thermo electric power (S) of Cadmium substituted Nickel Ferrites, forming chemical formula $\mathrm{Ni}_{1-\mathrm{x}} \mathrm{Cd}_{\mathrm{x}} \mathrm{Fe}_{2} \mathrm{O}_{4}$, where $\mathrm{x}=0.0,0.2,0.4$ have been investigated from room temperature to well beyond the Curie temperature. Plots of $\log (\sigma \mathrm{T})$ versus $10^{3} / \mathrm{T}$ are linear and show a transition near the Curie temperature. The transition temperature is found to decrease with increase of Cd content. On the basis of Seebeck coefficient (S), the ferrites under investigation have been classified as n-type and p-type semiconductors. The values of charge carrier concentration and mobility have been computed from experimental values of Seebeck coefficient and electrical conductivity. The activation energy in the ferrimagnetic region is in general less than that in the paramagnetic region. An attempt is made to explain the conduction mechanism in these ferrites.
\end{abstract}

Keywords: Ni-Cd Ferrite; Thermo Electric Power; Seebeck Coefficient; Charge Carrier Concentration; Electrical Conductivity

\section{Introduction}

The conditions of the preparation play an important role in site preference of the cations and all other properties of the spinal ferrites. The characteristic physical properties from the ability of the cation were distributed among the available tetrahedral A-site and octahedral B-site. The $\mathrm{NiFe}_{2} \mathrm{O}_{4}$ is completely inverse spine, because $\mathrm{Ni}^{2+}$ has a strong preference for the electrical conductivity octahedral site (B-site) [1]. Cadmium is the non magnetic divalent ions which occupy essentially tetrahedral A-site [2] when substituted in ferrites.

As far as the authors are aware of the study, the ac electrical conductivity and thermo electric power of the mixed Ni-Cd ferrites play as a function of composition and temperature. Therefore a systematic study of the electrical conductivity and thermo electric power of the mixed Ni-Cd ferrite system from room temperature to well beyond Curie temperature was undertaken. The results of such a study presented in this communication are explained on the basis of the hopping model.

\section{Experimental}

\subsection{Materials Preparation}

Specimens of the Ni-Cd ferrites having the compositional formula $\mathrm{Ni}_{1-\mathrm{x}} \mathrm{Cd}_{\mathrm{x}} \mathrm{Fe}_{2} \mathrm{O}_{4}$ where $\mathrm{x}=$ 0.0, 0.2, 0.4 were prepared by solgel method. The samples were presintered for $24 \mathrm{hr}$ in air at $600^{\circ} \mathrm{C}$.

\subsection{Methods}

Electrical conductivity measurements were made by the two probe method [3] from room temperature to well beyond the Curie temperature using a Keithley electrometer model 6517A. The electrical conductivity $(\sigma)$ of the $\mathrm{Ni}-\mathrm{Cd}$ ferrites under investigation has been computed using the formula,

$$
\sigma=\mathrm{It} / \mathrm{VA}
$$

where $I$ is the current passing through the specimen in amperes, $\mathrm{V}$ is the voltage applied to the specimen in volts, $\mathrm{t}$ is the thickness of the sample in $\mathrm{cm}$ and A denotes the area of the sample in $\mathrm{cm}^{2}$.

Thermo electric power studies were carried out as a function of composition and temperature by the differential method [4]. The sample holder for measuring the thermo emf consists of 2 pairs of non magnetic copper electrodes between which the sample is firmly fixed to the upper electrode for additional heating to maintain a temperature difference about $10 \mathrm{~K}$ between the 2 faces of the sample. A temperature of both surfaces of the sample 
was measured by 2 Chromel-Alumel thermo couples.

Thermo electric power (S) was calculated using the relation

$$
\mathrm{S}=\Delta \mathrm{E} / \Delta \mathrm{T}
$$

where $\Delta \mathrm{E}$ is the thermo emf produced across the sample due to the temperature difference $\Delta \mathrm{T}$.

\section{Results and Discussions}

\subsection{Composition Dependence of Lattice Parameter (a)}

$\mathrm{X}$-Ray Diffraction of all the ferrites under investigation has been obtained using Ni $\mathrm{K}_{\alpha}$ radiation. The XRD for $\mathrm{Ni}-\mathrm{Cd}$ ferrites are given in Figures 1-3. The lattice parameters of the mixed ferrites were calculated from d-spacings and are given in Table 1. It can be seen from the table that the value of lattice parameter increases with increase of cadmium content. The variation in the lattice parameter with $\mathrm{Cd}$ content is presented in Figure 4 (i.e., lattice parameter versus $\mathrm{Cd}$ content). It can be seen from the figure that the lattice parameter increases with increase in a $\mathrm{Cd}$ content.

It may be observed from the figure that the lattice parameter varies linearly with the $\mathrm{Cd}$ ion content. A similar linear dependence has also been observed in Ni-Zn [5], Mn-Zn [6], Li-Cd [7], Cd-Co [8] ferrites.

\subsection{Composition Dependence of Seebeck Coefficient (S)}

The values of the Seebeck coefficient of all mixed Ni-Cd ferrites were calculated from the observed values of the thermo emf and are given in Table 2. It can be seen that the sign of the Seebeck coefficient is negative for $\mathrm{x}=0$ and 0.2 compositions of the ferrites under investigation, indicating that the predominant conduction mechanism in these ferrites is of n-type semiconductors. From the observation, it follows that the predominant conduction mechanism in all the Ni-Cd ferrites is hopping of electrons [9] from $\mathrm{Fe}^{2+}$ to $\mathrm{Fe}^{3+}$ ions.

$$
\mathrm{Fe}^{3+}+\mathrm{e} \rightarrow \mathrm{Fe}^{2+}
$$

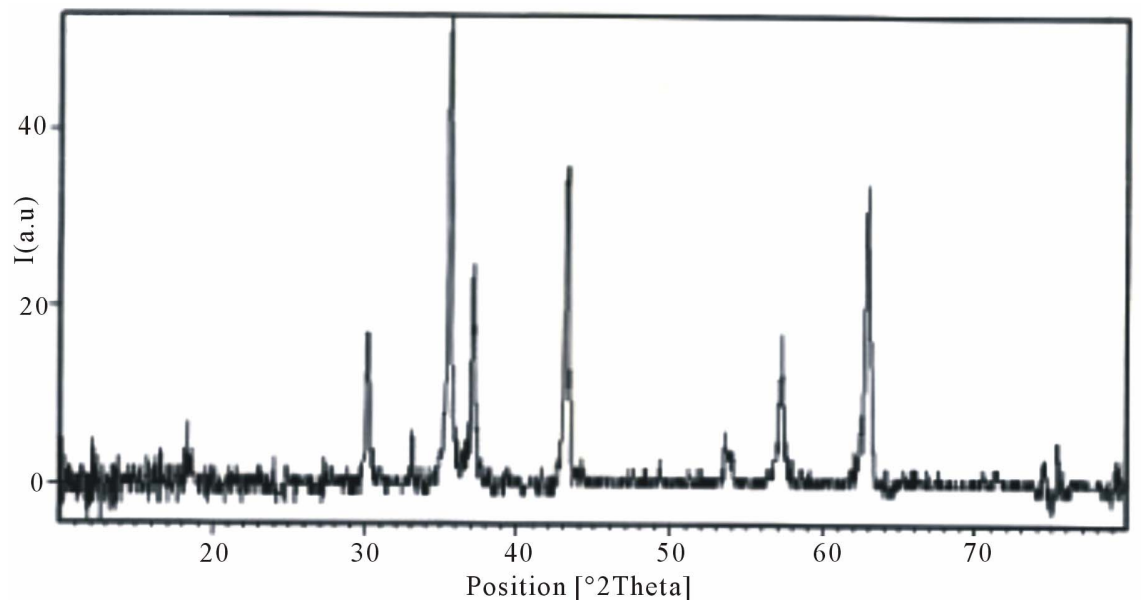

Figure 1. X-ray diffraction pattern for $\mathrm{NiFe}_{2} \mathrm{O}_{4}$ ferrite.

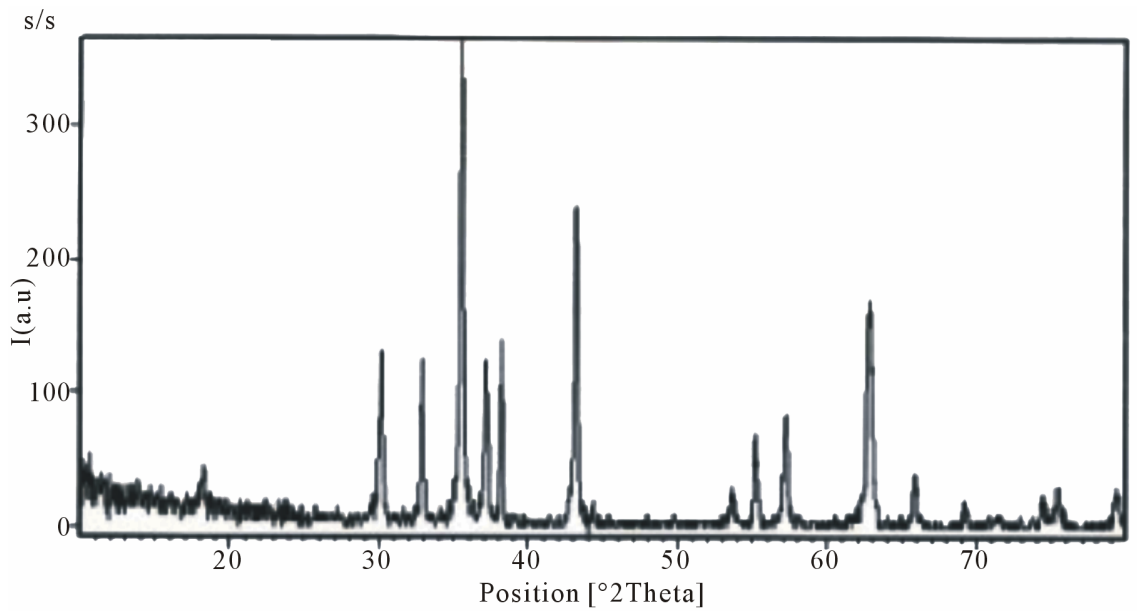

Figure 2. X-ray diffraction pattern for $\mathrm{Ni}_{0.8} \mathrm{Cd}_{0.2} \mathrm{Fe}_{2} \mathrm{O}_{4}$ ferrite. 


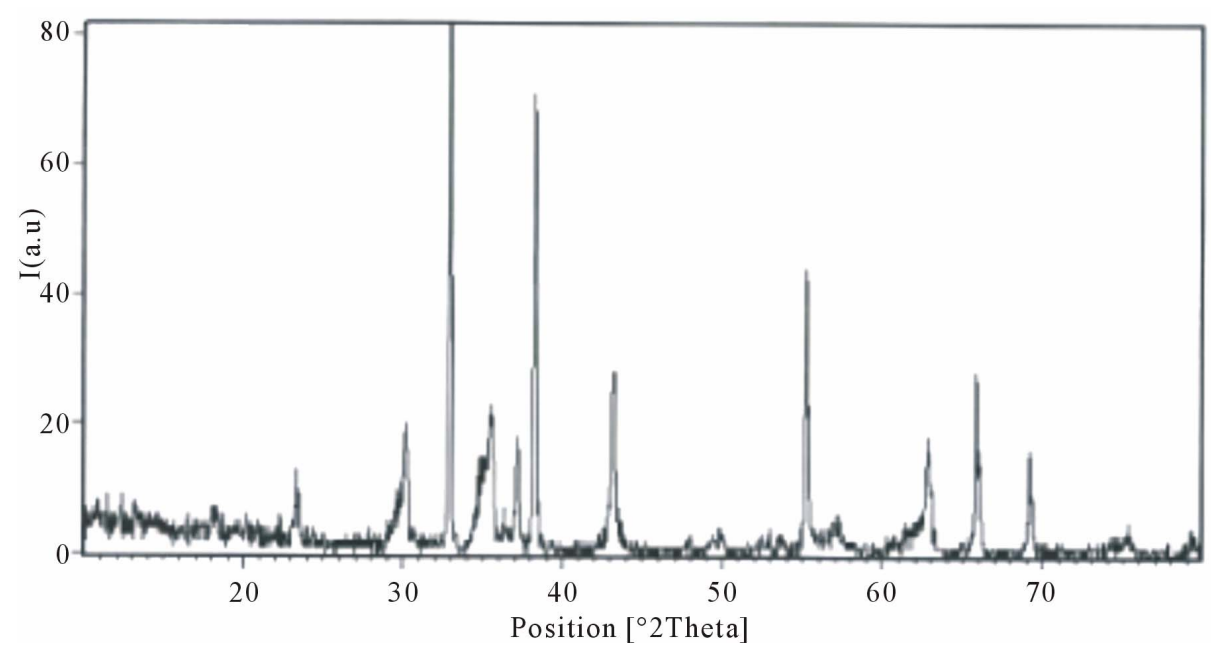

Figure 3. X-ray diffraction pattern for $\mathrm{Ni}_{0.6} \mathrm{Cd}_{0.4} \mathrm{Fe}_{2} \mathrm{O}_{4}$ ferrite.

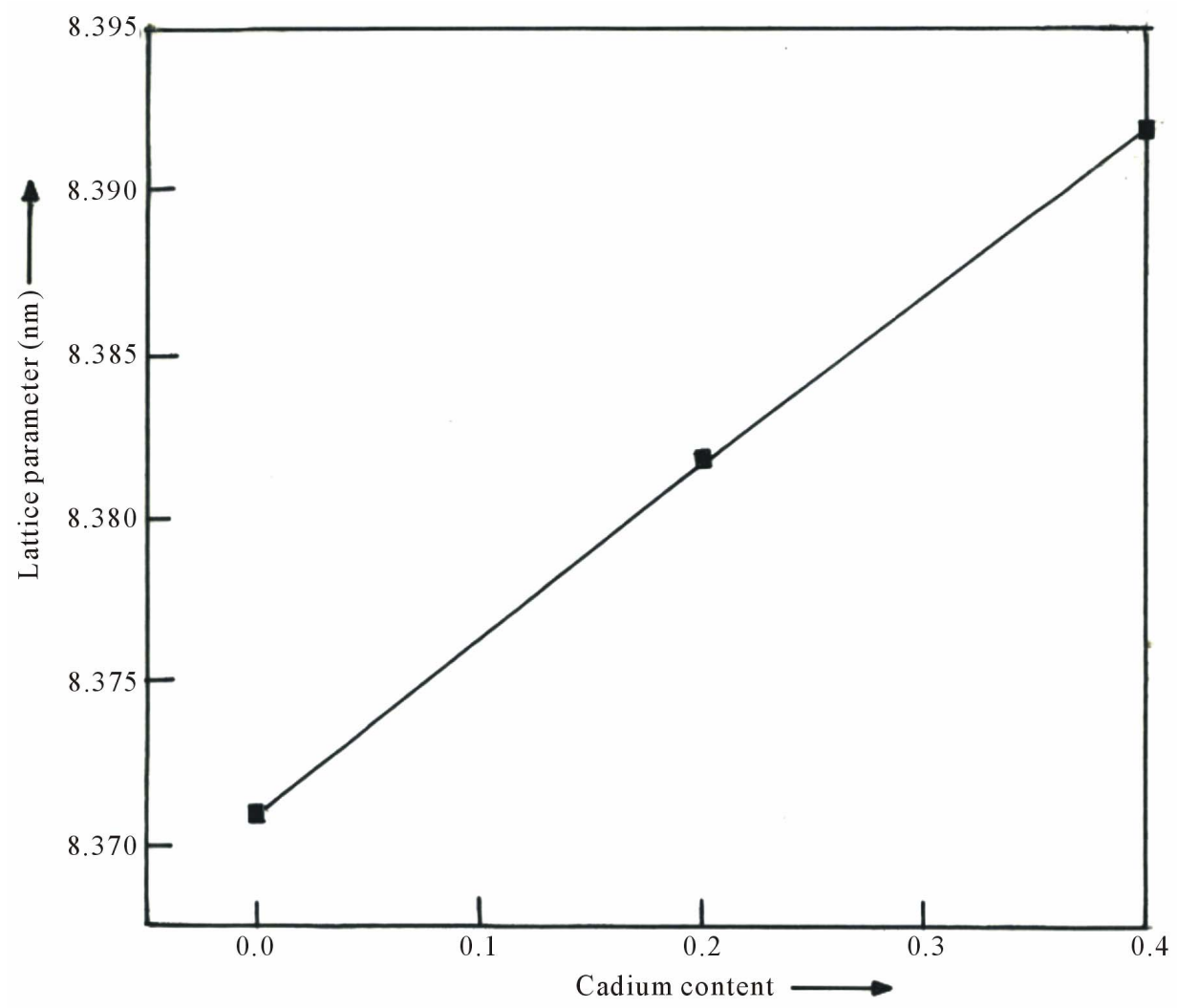

Figure 4. Variation of lattice parameter with cadmium content.

Table 1. Lattice parameter, density, crystalline size and volume data for Ni-Cd ferrites.

\begin{tabular}{cccccc}
\hline s. No & $\mathrm{X}$ & $\mathrm{a}(\AA)$ & Density $\left(\mathrm{gm} / \mathrm{cm}^{3}\right)$ & Crystalline size $(\AA)$ & Volume (V) \\
\hline 1 & 0.0 & 8.3709 & 5.30 & 5.05 & 586.5654 \\
2 & 0.2 & 8.3837 & 5.52 & 4.98 & 589.2603 \\
3 & 0.4 & 9.0185 & 5.57 & 4.58 & 733.5047
\end{tabular}


And the composition 0.4 for the Seebeck coefficient is positive and its conduction mechanism in these ferrites is of p-type semiconductors and it follows the hopping of holes.

The values of $\mathrm{S}$ are found to increase continuously from 0.0 to $0.2 \mu \mathrm{V} / \mathrm{K}$, with addition of cadmium from 0.0 to $0.4 \mathrm{~mol}$.

The variation of the Seebeck coefficient (S) with temperature is shown in Figure 5. It can be seen that the value of Seebeck coefficient increases with increase in temperature up to a certain temperature, which is designnated as the Seebeck coefficient transition temperature $\mathrm{T}_{\mathrm{s}}(\mathrm{K})$. However, beyond this temperature, the value of the Seebeck coefficient was found to decrease with increasing temperature. The negative value of the Seebeck coefficient was found over the entire temperature range studied and shows the majority charge carriers are electrons. In the case of positive value of the Seebeck coefficient were explained the majority charge carriers are holes and these results designated in Figure 6.

Table 2. Thermoelectric power data for mixed Ni-Cd ferrites.

\begin{tabular}{ccccccc}
\hline S.no. & Ferrite & $\begin{array}{c}\text { Seebeck coefficient } \\
\mathrm{S}(\mu \mathrm{V} / \mathrm{K})\end{array}$ & Type of semi conductor & $\begin{array}{c}\text { Seebeck coefficient transition } \\
\text { temperature }\end{array}$ & Curie temperture & $\mathrm{T}_{\mathrm{n}}(\mathrm{K})$ \\
\hline 1 & $\mathrm{NiFe}_{2} \mathrm{O}_{4}$ & -1419 & n-type & 458 & 438 & 438 \\
2 & $\mathrm{Ni}_{0.8} \mathrm{Cd}_{0.2} \mathrm{Fe}_{2} \mathrm{O}_{4}$ & -850 & n-type & 453 & 433 & 432 \\
3 & $\mathrm{Ni}_{0.6} \mathrm{Cd}_{0.4} \mathrm{Fe}_{2} \mathrm{O}_{4}$ & 10 & p-type & 368 & 373 & 370 \\
\hline
\end{tabular}

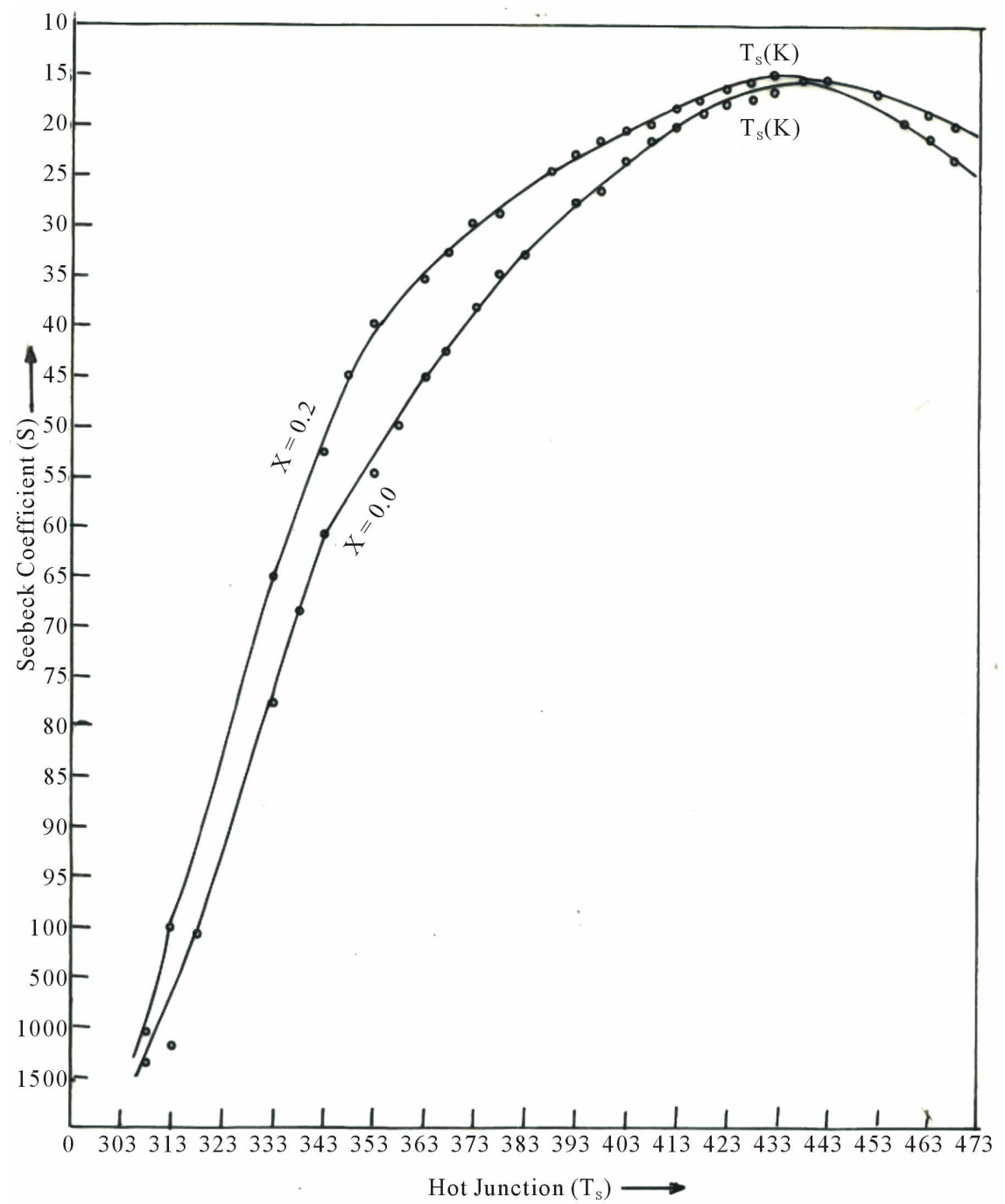

Figure 5. Plot of Seebeck coefficient (S) verses temperature for $\mathrm{Ni}_{1-x} \mathrm{Cd}_{x} \mathrm{Fe}_{2} \mathrm{O}_{4}$ Ferrites (Where $x=0.0$ and 0.2 ). 


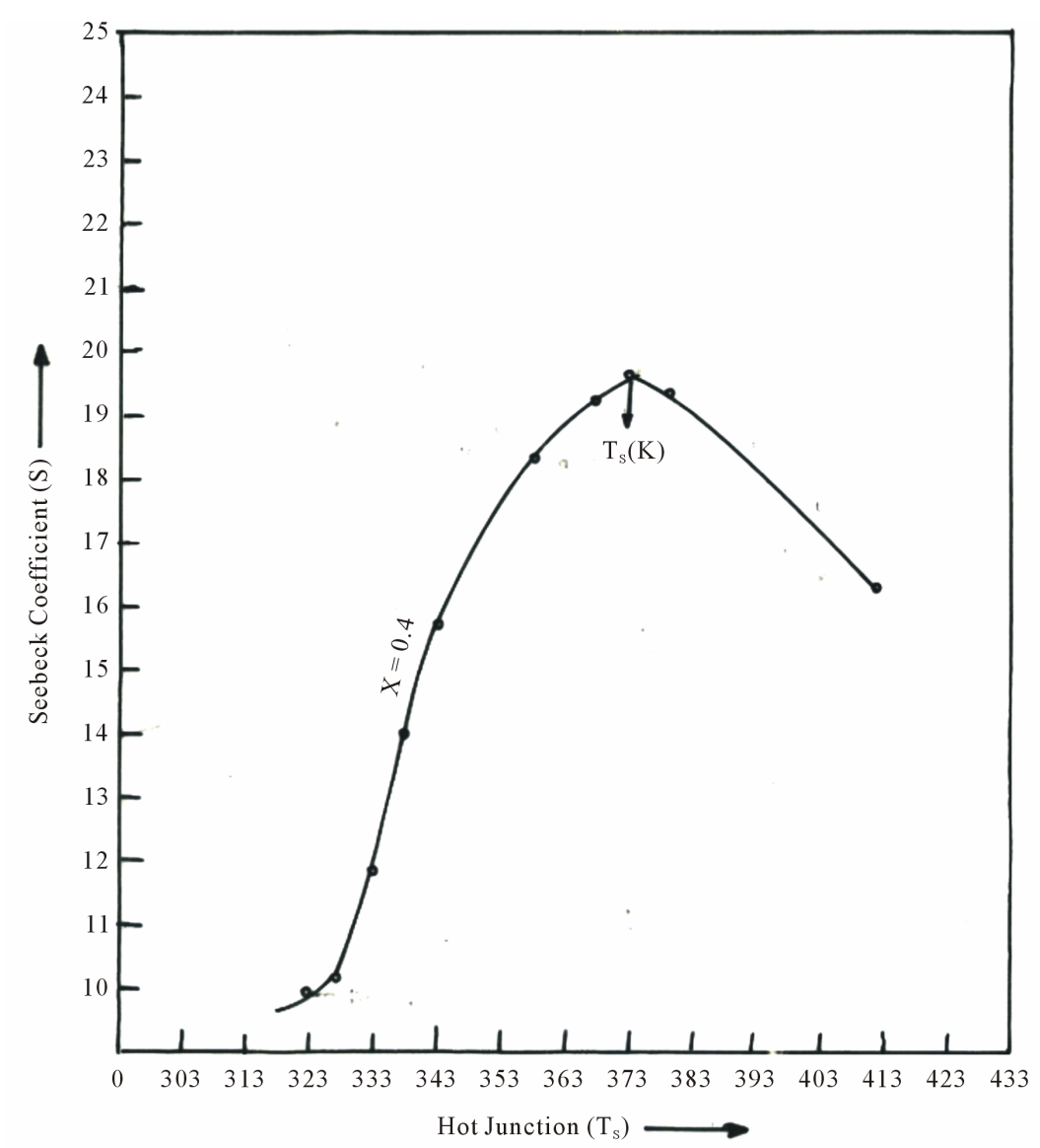

Figure 6. Plot of Seebeck coefficient (S) verses temperature for $\mathrm{Ni}_{0.6} \mathrm{Cd}_{0.2} \mathrm{Fe}_{2} \mathrm{O}_{4}$.

The values of $\mathrm{T}_{\mathrm{s}}(\mathrm{K})$ for each composition are given in Table 2. The curie is for the purpose of comparison. It can be seen that the value of $\mathrm{T}_{\mathrm{s}}(\mathrm{K})$ and $\mathrm{T}_{\mathrm{c}}(\mathrm{K})$ are in good agreement. The transition temperatures obtained in the present investigation in all the mixed $\mathrm{Ni}-\mathrm{Cd}$ ferrites may be attributed to ferrimagnetic to paramagnetic transitions. A similar result has been reported by Whall et al. $[10,11]$ in the case of Manganese and Lithium ferrites.

\subsection{Electrical Conductivity $(\sigma)$}

Table 3 gives the experimental values of electrical conductivity and Seebeck coefficient values at room temperature. The carrier concentration for these ferrites was calculated using the formula given by morin and gebella [12].

$$
\mathrm{n}=\mathrm{N} \exp (-\mathrm{Se} / \mathrm{k})
$$

where $\mathrm{S}$ is seebeck coefficient; e is charge of electron; $\mathrm{k}$ is Boltzmann constant; $\mathrm{N}$ is density of states or concentration of electronic levels involved in the conduction process.

An examination of Table 3 reveals that the electrical conductivity of the mixed $\mathrm{Ni}-\mathrm{Cd}$ ferrites is found to decrease with an increase in cadmium content to $0.4 \mathrm{~mol}$.
This shows that $\mathrm{Ni}_{0.6} \mathrm{Cd}_{0.4} \mathrm{Fe}_{2} \mathrm{O}_{4}$ poses the highest resistivity among all the compositions investigated from the Table 3 that the $\mathrm{Ni}_{0.6} \mathrm{Cd}_{0.4} \mathrm{Fe}_{2} \mathrm{O}_{4}$ composition has the high electrical conductivity correspondingly, the high electrical conductivity for this specimen has a value of $2.6469 \times 10^{-5} \mathrm{ohm}^{-1} \mathrm{~cm}^{-1}$. This high value can be explained on the basis of the fact that it has a maximal no. of ferrous ions whose exchange $\mathrm{Fe}^{2+} \Leftrightarrow \mathrm{Fe}^{3+}$ gives rise to a maximal electrical conductivity. Table 3 reveals that the variation of the electrical conductivity of $\mathrm{Cu}-\mathrm{Cd}$ ferrites runs parallel to the variation of available ferrous ions on octahedral sites. It is significant to note that $\mathrm{Ni}_{1-\mathrm{x}}$ $\mathrm{Cd}_{\mathrm{x}} \mathrm{Fe}_{2} \mathrm{O}_{4}$, has the lowest ferrous ion concentration and possesses the lowest electrical conductivity. It is also pertinent to mention that the variation of electrical conductivity with the composition Table 3 runs parallel to the variation of the ferrous ions concentration [13]. Thus it is the number of ferrous ions on octahedral sites that place a dominant role in the process of conduction. This result is in agreement with the assumption of Rabankin and Novikova [13]. The temperature dependence of electrical conductivity of mixed Ni-Cd ferrites of different compositions has been investigated from room temperature to well beyond the Curie temperature. Figures 7-9 gives 
Table 3. Electrical conductivity for Ni-Cd ferrites at room temperature.

\begin{tabular}{ccccc}
\hline S. No & Ferrite & $\mathrm{T}_{\mathrm{s}}(\mathrm{K})$ & Electrical conductivity $\sigma\left(\Omega^{-1} \mathrm{~cm}^{-1}\right)$ & Electrical resistivity $\rho(\Omega \mathrm{cm})$ \\
\hline 1 & $\mathrm{NiFe}_{2} \mathrm{O}_{4}$ & 458 & $9.3489 \times 10^{-3}$ & $1.07 \times 10^{4}$ \\
2 & $\mathrm{Ni}_{0.8} \mathrm{Cd}_{0.2} \mathrm{Fe}_{2} \mathrm{O}_{4}$ & 453 & $3.7623 \times 10^{-4}$ & $2.66 \times 10^{5}$ \\
3 & $\mathrm{Ni}_{0.6} \mathrm{Cd}_{0.4} \mathrm{Fe}_{2} \mathrm{O}_{4}$ & 368 & $2.6469 \times 10^{-4}$ & $3.78 \times 10^{5}$ \\
\hline
\end{tabular}

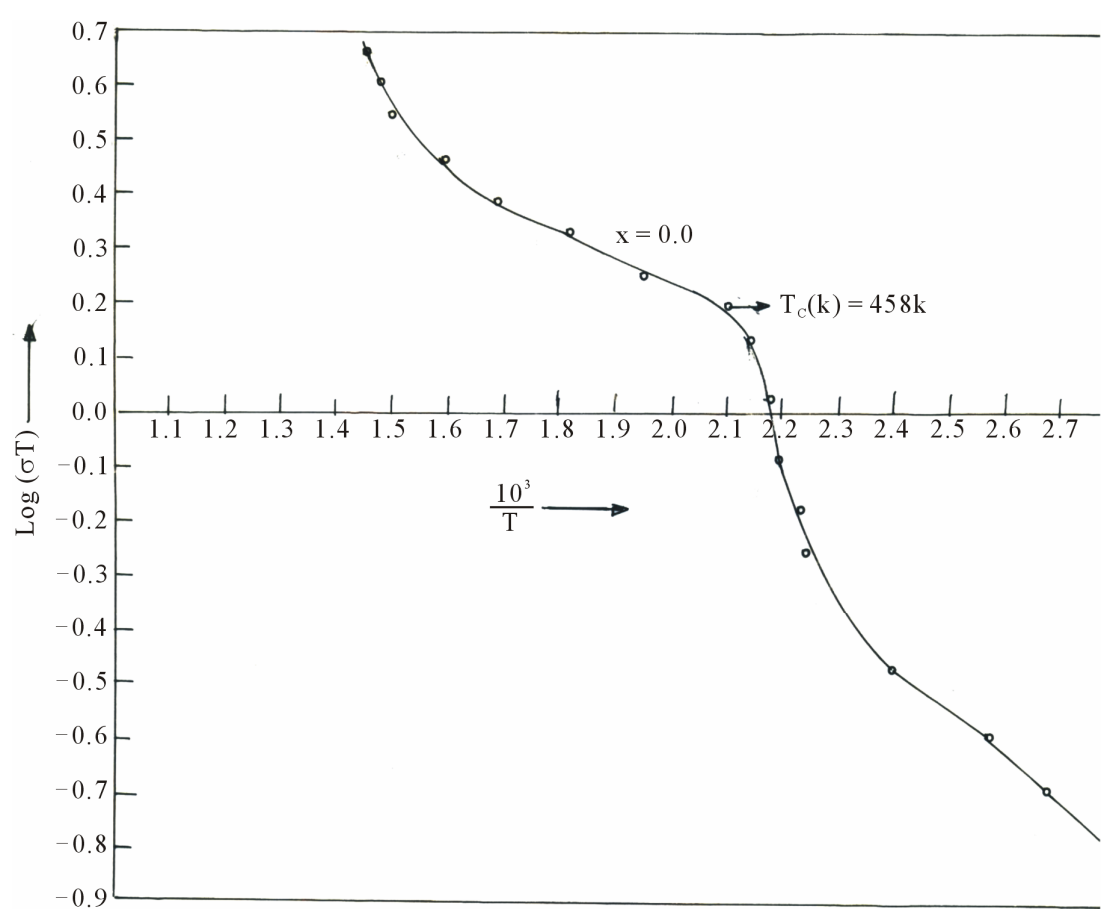

Figure 7. Plot of $\log (\sigma \mathrm{T})$ versus $10^{3} / \mathrm{T}$ for $\mathrm{NiFe}_{2} \mathrm{O}_{4}$.

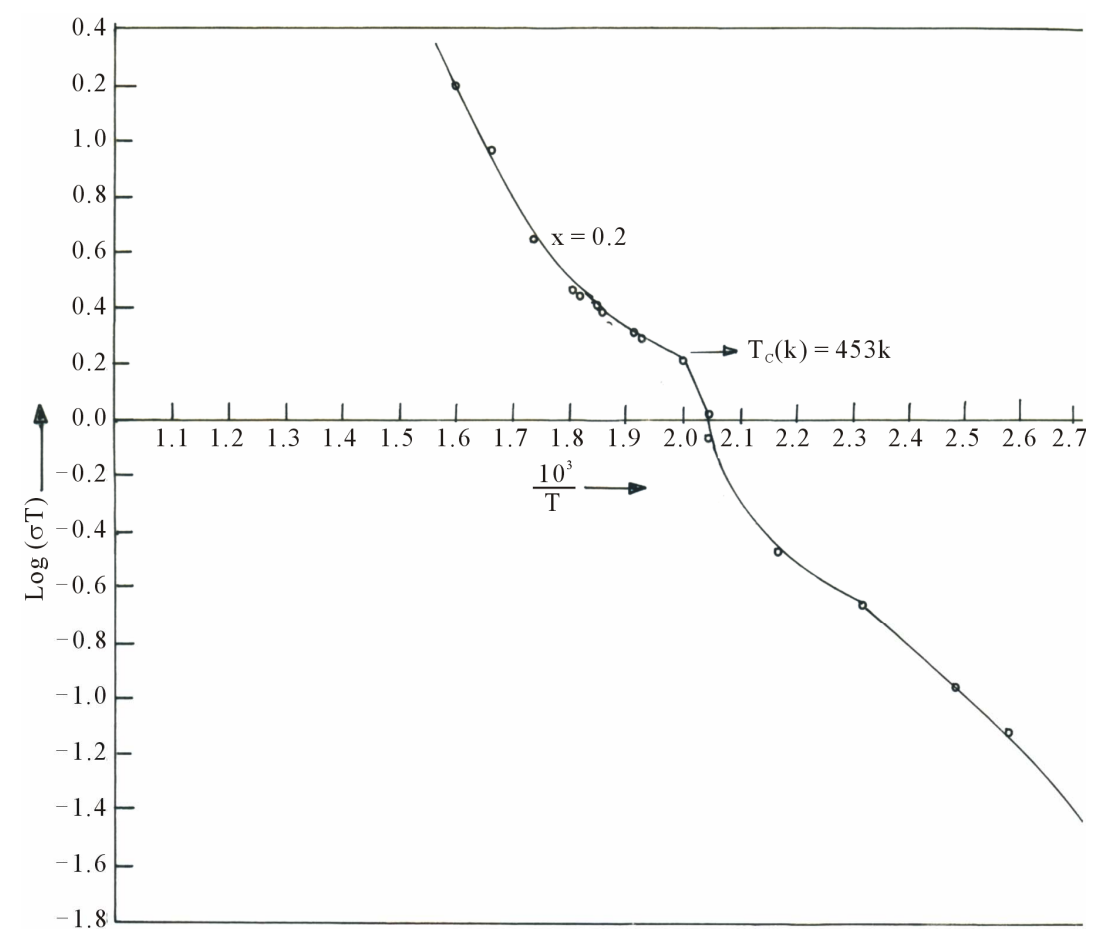

Figure 8. Plot of $\log (\sigma \mathrm{T})$ versus $10^{3} / \mathrm{T}$ for $\mathrm{Ni}_{0.8} \mathrm{Cd}_{0.2} \mathrm{Fe}_{2} \mathrm{O}_{4}$. 


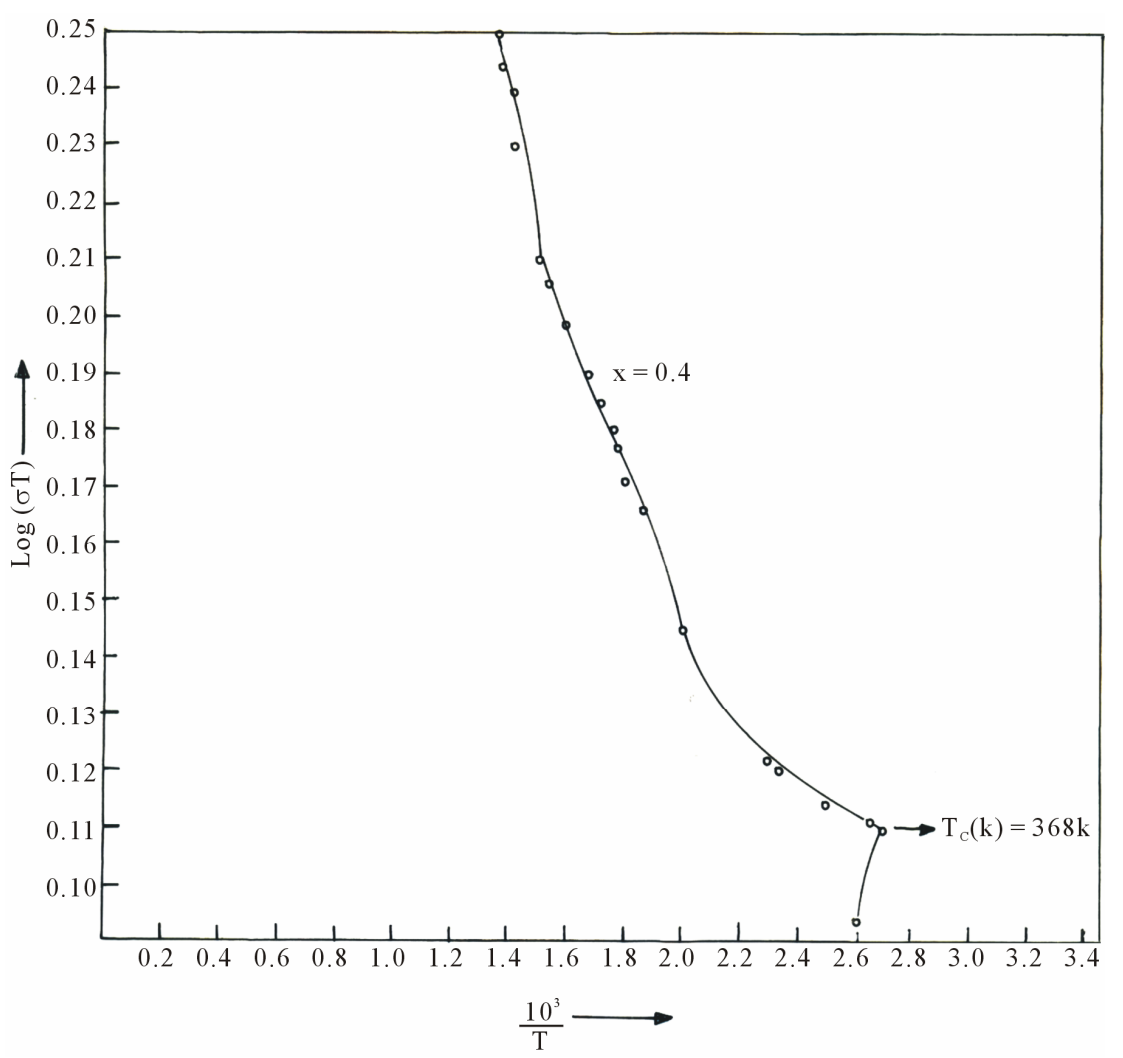

Figure 9. Plot of $\log (\sigma \mathrm{T})$ versus $10^{3} / \mathrm{T}$ for $\mathrm{Ni}_{0.6} \mathrm{Cd}_{0.4} \mathrm{Fe}_{2} \mathrm{O}_{4}$.

gives a plot of $\log (\sigma \mathrm{T})$ versus $10^{3} / \mathrm{T}$. It can be seen that the value of $\log (\sigma \mathrm{T})$ increases linearly with increaseing temperature up to a certain temperature $\mathrm{T}_{\mathrm{s}}(\mathrm{K})$ at which a change of slope has occurred.

The activation energies in the ferromagnetic and paramagnetic regions are calculated from the slopes of plots of $\log (\sigma \mathrm{T})$ versus $10^{3} / \mathrm{T}$ and presented in Table 4. The activation energy in the paramagnetic region is higher than that in the ferromagnetic region.

A high activation energy goes hand in hand with a low conductivity of the ferrites. Similar result was observed by samokhralov and rustmov [14]. The activation energy decreases with increase in cadmium content. The magnitude of the kink as determined by the difference between the activation energies in the paramagnetic and ferromagnetic regions $(\Delta \mathrm{E})$ which is given in column (5) of Table 4. Column 5 of the Table 3 gives the values of resistivity for the specimens under investigation. An inspection of these results reveals that $(\Delta \mathrm{E})$ decreases as resistivity decreases.

Generally, the change of slope is attributed to change in conductivity mechanism. The conduction at a lower temperature ( below curie temperature) is due to hopping of electrons [15] between $\mathrm{Fe}^{2+}$ and $\mathrm{Fe}^{3+}$ ions, where as at a higher temperature (above curie temperature) due to hopping of polarons [16-18]. The calculated values of activation energy in a paramagnetic region $\left(E_{2}\right)$ are greater than $0.40 \mathrm{eV}$ which clearly suggest that the conduction is due to hopping of polarons.

\section{4. charge Carrier Mobility $(\mu)$}

The charge carrier mobility $(\mu)$ of mixed Ni-Cd ferrites was calculated from the experimental values of electrical conductivity $(\sigma)$ and charge carrier concentration (n) using the relation.

$$
\sigma=\text { ne } \mu
$$

where $\mathrm{e}$ is the exchange of electron.

The calculated values of the mobility are given in Table 4 . It can be seen that the value of the mobility varies from $4.95 \times 10^{-6}$ to $1.65 \times 10^{-9} \mathrm{~cm}^{2} / \mathrm{VS}$. Such low values of mobility have been reported by several researches [19-22]. The variation of charge carrier mobility values increases continuously with increasing temperature. The increase in mobility with an increase in temperature suggests that the conduction in these ferrites is due to a hopping mechanism of electrons from $\mathrm{Fe}^{2+}$ to $\mathrm{Fe}^{3+}$.

\subsection{Temperature Variation of Charge Carrier Concentration (n)}

The temperature variation of charge carrier concentration is shown in Figures 10-12. It can be seen from the figures that the charge carrier concentration increases 
Table 4. Activation energies, Charge carrier concentration and mobility for Ni-Cd ferrites.

\begin{tabular}{|c|c|c|c|c|c|c|}
\hline \multirow{2}{*}{ S. No } & \multirow{2}{*}{$\mathrm{x}$} & \multicolumn{3}{|c|}{ Activation énergies (eV) } & \multirow{2}{*}{ Carrer concentration $(\mathrm{cm})$} & \multirow{2}{*}{ Mobility $\mathrm{cm}^{2} / \mathrm{VS}$} \\
\hline & & $\mathrm{FM} \mathrm{E}_{1}(\mathrm{eV})$ & $\mathrm{PM} \mathrm{E}_{2}(\mathrm{eV})$ & $\mathrm{E}(\mathrm{ev})$ & & \\
\hline 1 & 0.0 & 0.89 & 0.91 & 0.90 & $11.788 \times 10^{22}$ & $4.9568 \times 10^{-6}$ \\
\hline 2 & 0.2 & 0.63 & 0.75 & 0.69 & $10.997 \times 10^{22}$ & $2.1383 \times 10^{-8}$ \\
\hline 3 & 0.4 & 0.41 & 0.52 & 0.46 & $9.9676 \times 10^{22}$ & $1.6597 \times 10^{-9}$ \\
\hline
\end{tabular}

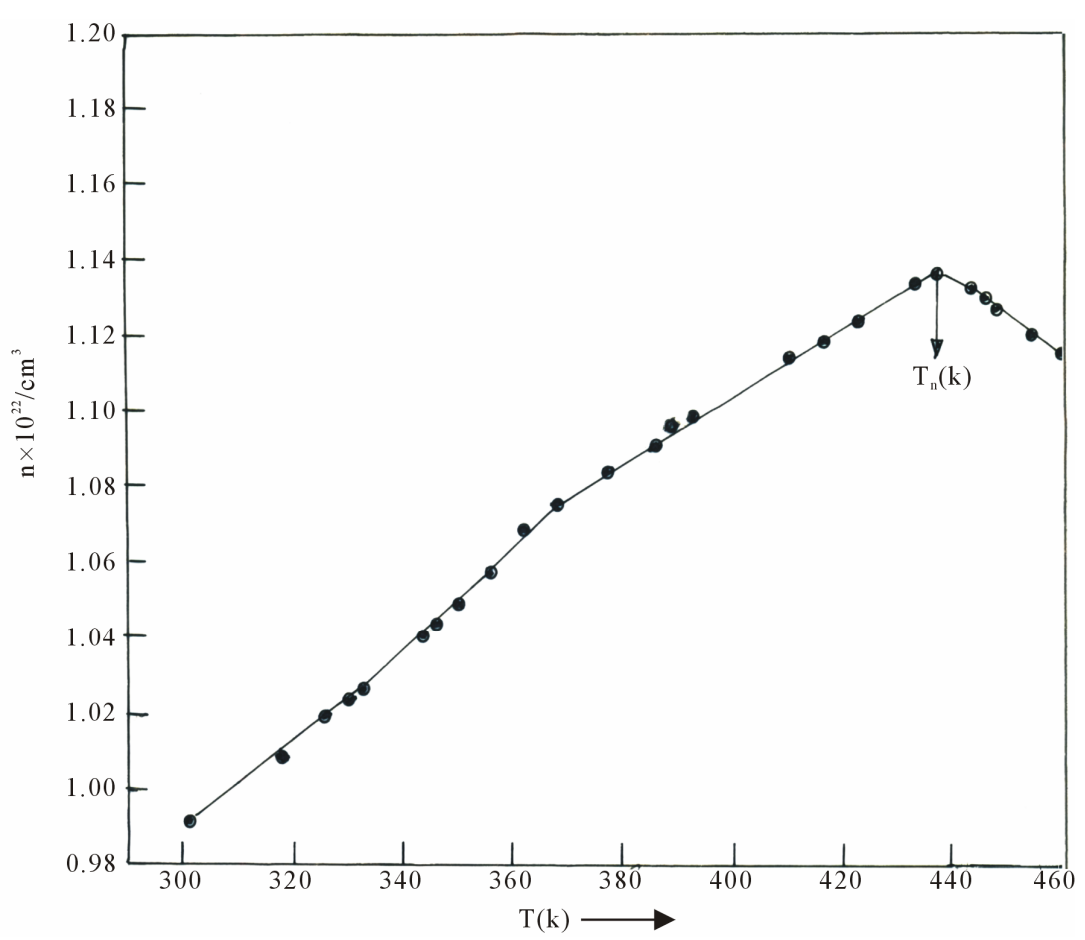

Figure 10. Variation of charge carrier concentration with temperature for $\mathrm{Ni}_{0.8} \mathrm{Cd}_{0.2} \mathrm{Fe}_{2} \mathrm{O}_{4}$.

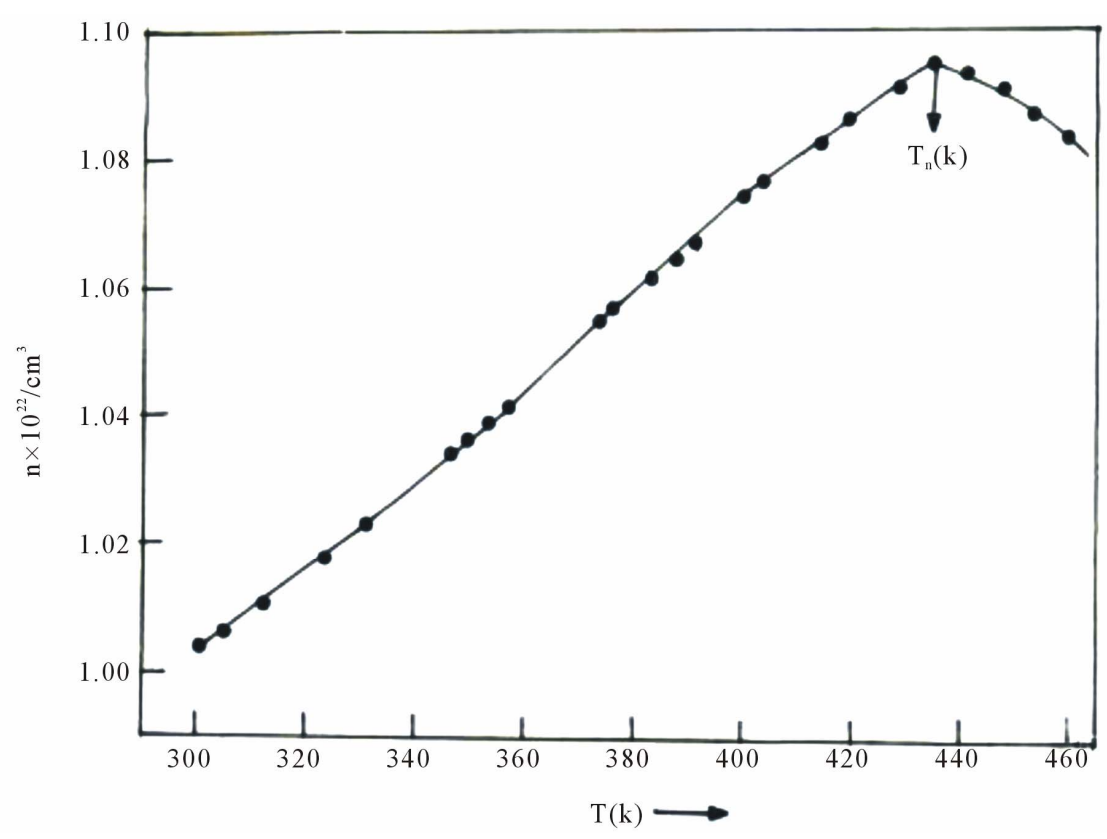

Figure 11. Variation of charge carrier concentration with temperature for $\mathrm{NiFe}_{2} \mathrm{O}_{4}$. 


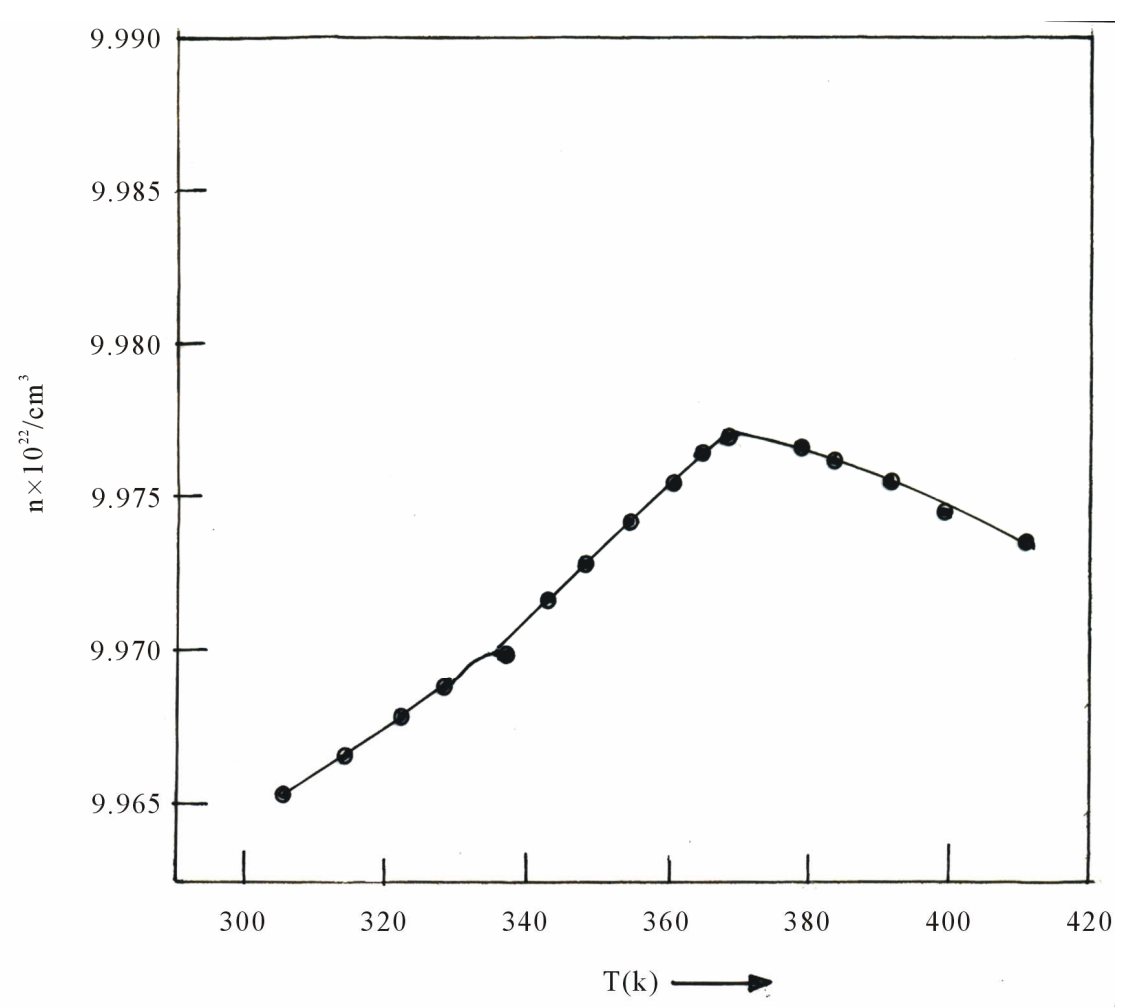

Figure 12. Variation of charge carrier concentration with temperature for $\mathrm{Ni}_{0.6} \mathrm{Cd}_{0.4} \mathrm{Fe}_{2} \mathrm{O}_{4}$.

with increase in temperature continuously up to $T_{n}(K)$. However above this temperature the carrier concentration decreases continuously for all the ferrites. The values of $\mathrm{T}_{\mathrm{n}}(\mathrm{K})$ for all the ferrites under investigation are listed and compared with their respective curie temperatures in Table 2 . It can be seen that values of $T_{n}(K)$ and $T_{c}(K)$ are in good agreement. Similar variations of $n$ and $T$ were also observed by Reddy and Mulay et al. in the case of Li-Ti [23] and $\mathrm{Mg}-\mathrm{Al}$ [24] ferrites.

\section{Acknowledgements}

The authors are grateful to Prof. Naidu Ashoak, Principal Nizam college, Osmania University and Prof. P. Kistaiah, Head, Department of Physics, Osmania University for their encouragement to carry out research work.

\section{REFERENCES}

[1] Kh. Roumaiah, "The Transport Properties of the Mixed Ni-Cu Ferrite," Journal of Alloys and Compounds, Vol. 465, 2008, pp. 291-295.

[2] H. N. Oak, K. S. Baek and S. J. Kim, "Mössbauer Studies of Superexchange Interaction in Tetragonal $\mathrm{CuFe}_{2} \mathrm{O}_{4}$," Solid State Physics, Vol. 208, No. 1, 1998, pp. 249-255. doi:10.1002/(SICI)1521-3951(199807)208:1<249::AID-P SSB249>3.0.CO;2-B

[3] C. B. Kolekar, P. N. Kamble and S. G. Kulkarni, "Effect of $\mathrm{Gd}^{3+}$ Substitution on Dielectric Behaviour of Cop-
per-Cadmium Ferrites," Journal of Materials Science, Vol. 30, No. 22, 1995, pp. 5784-5788. doi:10.1007/BF00356721

[4] V. R. Kulkarni and A. S. Vainganker, "Abnormal Dielectric Behaviour in the $\mathrm{Cd}_{\mathrm{x}} \mathrm{Cu}_{1-\mathrm{x}} \mathrm{Fe}_{2} \mathrm{O}_{4}$ System," Journal of Materials Science, Vol. 22, 1987, pp. 4087-4092. doi:10.1007/BF01133362

[5] N. Rezlescu and E. Rezlescu, "Dielectric Properties of Copper Containing Ferrites," Physica Status Solidi (A), Vol. 23, No. 2, 1974, pp. 575-582. doi: $10.1002 /$ pssa. 2210230229

[6] D. Ravinder, K. Vijaya Kumar and B. S. Boyanov, "Elastic Behaviour of Cu-Zn Ferrites," Materials Letters, Vol. 25, 1999, pp. 22-27.

[7] D. Ravinder and T. Seshagiri Rao, "Electrical Conductivity and Thermoelectric Power of Lithium-Cadmium Ferrites," Crystal Research and Technology, Vol. 25, No. 8, 1990, pp. 963-969. doi:10.1002/crat.2170250820

[8] V. D. Reddy, M. A. Malik and P. V. Reddy, "Electrical Transport Properties of Manganese-Magnesium Mixed Ferrites," Materials Science and Engineering: B, Vol. 8, No. 4, 1991, pp. 295-301. doi:10.1016/0921-5107(91)90050-6

[9] D. Ravinder, "Electrical Transport Properties of Cadmium Substituted Copper Ferrites," Materials Letters, Vol. 43, 2000, pp. 129-138. doi:10.1016/S0167-577X(98)00126-8

[10] A. Globus, H. Pascord and V. Cagan, Physica, Vol. 86-88, 1997, p. 1452.

[11] D. Ravinder and T. Seshagiri Rao, "Electrical Conductiv- 
ity and Thermoelectric Power of Lithium-Zinc Ferrites," Crystal Research and Technology, Vol. 25, 1990, pp. 1079-1085. doi: $10.1002 / \mathrm{crat} .2170250820$

[12] D. Ravinder and P. K. Raju, "Composition Dependence of the Elastic Moduli of Mixed Lithium-Zinc Ferrites," Physica Status Solidi (A), Vol. 136, No. 2, 1993, pp. 351356. doi:10.1002/pssa.2211360208

[13] L. I. Rabinkin and Z. I. Novikova, Ferrites, Minsk, 1960.

[14] A. A. Samokhralov and A. G. Rustmov, Soviet PhysicsSolid State, Vol. 7, 1965, p. 961.

[15] L. G. Van Uitert, "High-Resistivity Nickel Ferrites-The Effect of Minor Additions of Manganese or Cobalt," Journal of Chemical Physics, Vol. 24, No. 2, 1956, pp. 306-310. doi:10.1063/1.1742468

[16] M. I. Klinger, "Two-Phase Polaron Model of Conduction in Magnetite-Like Solids," Journal of Physics C: Solid State Physics, Vol. 8, No. 21, 1975, p. 3595. doi:10.1088/0022-3719/8/21/029

[17] N. F. Mott and R. W. Gurney, "Electronics Process in Ionic Crystals," Oxford University Press, Oxford, 1948.

[18] M. I. Klinger, "Electron conduction in magnetite and ferrites," Physica Status Solidi (B), Vol. 79, No. 1, 1977, pp. 9-48. doi:10.1002/pssb.2220790102

[19] I. Bunget, Rev. Roum. Phys., Vol. 15, 1970, p. 433.

[20] B. Gillot and F. Jemmali, "Dependence of Electrical Pro-
Perties in Iron-Cobalt, Iron-Zinc Ferrites near StoichioMetry on Firing Temperature and Atmosphere," Physica Status Solidi (A), Vol. 76, No. 2, 1983, pp. 601-608. doi:10.1002/pssa.2210760223

[21] J. A. Kulkarni, V. Muralidharan, J. K. Srivastava, V. R. Maratha, V. S. Darshane, C. R. K. Murthy and V. Raghavan, "Structural, Magnetic and Transport Properties of the Spinel Ferrites $\mathrm{Ga}_{\mathrm{x}} \mathrm{Fe}_{1-\mathrm{x}} \mathrm{NiCrO}_{4}$," Journal of Physics C: Solid State Physics, Vol. 18, No. 13, 1985, p. 2593. doi:10.1088/0022-3719/18/13/006

[22] Md. Abdul Malik, V. D. Reddy, P. Venugopal Reddy, D. R. Sagar and Prankishan, "Charge Transport in Germanium-Substituted Magnesium Ferrites," Modern Physics Letters B, Vol. 8, No. 16, 1994, p. 947. doi:10.1142/S0217984994000959

[23] M. Bhagavantha Reddy, V. N. Moolay, V. Devendar Reddy and P. Venugopal Reddy, "Charge transport in mixed Li Ti ferrites," Materials Science and Engineering: B, Vol. 14, No. 1, 1992, pp. 63-69. doi:10.1016/0921-5107(92)90330-C

[24] V. N. Moolay, K. Bhupal Reddy, V. Devendar Reddy and P. Venugopal Reddy, "Electrical Transport Properties of Copper Substituted Magnesium Aluminium Ferrites," Physica Status Solidi (A), Vol. 130, No. 2, 1992, pp. 397-406. doi: $10.1002 /$ pssa.2211300217 